rapidly advancing spinal cord compression. ${ }^{4}$ A normal cell count in the C.S.F., an increase in protein, and a more or less complete block on myelography are to be expected. 5 According to Arseni and Samitca ${ }^{4}$ it is difficult, if not impossible, to differentiate between extramedullary and intramedullary tuberculoma before surgery as the radiological picture in both is identical. To the best of our knowledge this is the first case described showing the true intramedullary nature of a tuberculoma before surgery. It draws attention to the unusual presentations of tuberculosis in the immigrant population and adds another cause to the radiological list of intramedullary spinal lesion.

We are grateful to the Department of Medical Photography, Leeds (St. James's) University Hospital, for preparing the illustrations and to Mrs. Jacqueline Buck for preparing the typescript.

1 Wiseman, R. A., and Mahmood, A., British fournal of Clinical Practice, $1967,21,13$.

2 Dibble, J. B., and Cascino, J., Fournal of the American Medical Association, 1956, 162, 461.

3 Lin, T. H., Fournal of Neurosurgery, 1960, 17, 497

Arseni, C., and Samitca, D. C., Brain, 1960, 83, 285.

5 Kocen, R. S., and Parsons, M., Quarterly fournal of Medicine, 1970, 39, 17.

Department of Diagnostic Radiology, Chapel Allerton Hospital, Leeds LS7 4RB

E. R. BRESNIHAN, M.B., D.oBsT.R.C.o.G., Senior Registrar

J. T. LAMB, M.B., F.F.R., Consultant Neuroradiologist

\section{Intra-arterial monitoring of critically ill patients in ambulances}

Continuous recording of blood pressure (BP) by intra-arterial catheter during ambulance transport has not previously been reported. We here report a study of this.

\section{Patients, methods, and results}

Eleven critically ill patients were studied during ambulance transfer from other hospitals to an intensive therapy unit (ITU). Full resuscitation, anaesthetic, and monitoring equipment was available on a self-contained trolley. Blood pressure, recorded via a radial artery catheter and semiconductor strain-gauge transducer (Elcomatic EM 750) was displayed together with the electrocardiograph on an oscilloscope (Rigel DM 722). A time division multiplexing system allowed this information to be recorded on an FM magnetic tape recorder (Tandberg Series 100). Movement was recorded using triaxially arranged accelerometers (Kulite GY/125/100) on the patient's chest.

Transfer did not begin till the patients were resuscitated and stabilised. Continuous recordings were made for 20 minutes in bed before movement throughout all phases of the journey and for 20 minutes thereafter. During transfer eight patients received intermittent positive pressure ventilation (IPPV) using a Harlow ventilator. Mean distance travelled was 10 miles $(16 \mathrm{~km})$.

Two patients developed sustained hypertension of $30-50 \mathrm{~mm} \mathrm{Hg}$, apparently related to inadequate IPPV with hypercapnia. One patient, receiving an isoprenaline infusion, had a slow fall in BP from $100 / 65$ to $85 / 50 \mathrm{~mm} \mathrm{Hg}$, again probably related to changed IPPV. A further seven patients showed transient episodes of hypertension, one patient having repeated rises to $200 / 115 \mathrm{~mm} \mathrm{Hg}$. Transient hypertension was significantly more frequent $(P<0.0005)$ during movement to and from the ambulance (see fig). Only four episodes of transient hypotension, each lasting 20-90 seconds, were observed in two patients. Three of the four episodes occurred when the patients were lifted on or off the trolley and only one during the ambulance ride. Seven patients had ventricular extrasystoles, with a significant increase in frequency $(P<0.0005)$ during movement to and from the ambulance (see fig). In most patients the extrasystoles were probably of no clinical significance but in one patient ventricular tachycardia required lignocaine.

There were no instances of sudden collapse, sustained arrhythmia, acute respiratory insufficiency, or fits. All the reported effects disappeared either spontaneously or with adjustment of treatment.

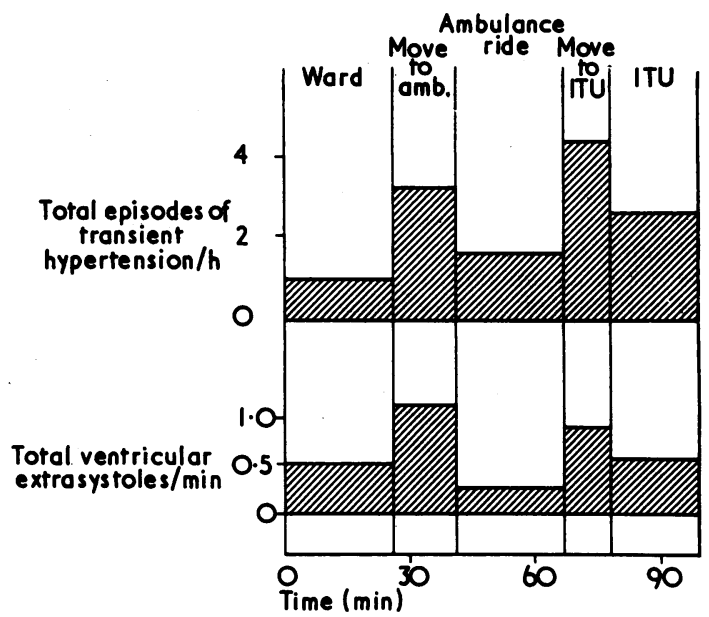

Total episodes of transient hypertension and ventricular extrasystoles seen in 11 critically ill patients during ambulance transfer between hospitals.

\section{Discussion}

The striking feature of this study was the overall cardiovascular stability. The effects of ambulance transport may be direct or indirect. ${ }^{1}$ Discomfort, pain, and the physical stimuli of movement may directly affect the patient's condition. Indirectly, lack of facilities and the motion of the ambulance may reduce the ability of attendants to provide life support, affecting the patient by changed or inadequate treatment. In this, as in our previous study, ${ }^{2}$ the few sustained effects appeared to be caused indirectly. By contrast, direct effects of the journey appeared to be transient. Hypertension was much more common than hypotension, despite the emphasis on the latter in previous reports. ${ }^{1}$ Hypertension is a common response to other types of stress and has been found in healthy people on a vibration table and in dogs with haemorrhagic shock subjected to repeated jolting."

All the transient effects-hypertension, hypotension, and ventricular extrasystoles-were more frequent during movement to and from the ambulance. Such movement may be at least as hazardous as the actual ambulance ride, particularly since movement of critically ill patients within hospital may be harmful. ${ }^{5}$

The clinical significance of these transient effects remains uncertain, although none was observed to result in a deterioration in the patient's general condition. This new information has not altered the basic conclusion that critically ill patients may be safely transported. Nevertheless, knowledge of the transient phenomena reported here may facilitate the development of further measures to forestall harm.

Funds to develop the monitoring equipment came from the Army Personnel Research Council (Medical Research Council). Ventilatory equipment was supplied by the British Oxygen Company.

1 Snook, R, British Medical fournal, 1972, 3, 574.

2 Waddell, G, et al, British Medical fournal, 1975, 1, 386.

3 Hood, W B, et al, fournal of Applied Physiology, 1966, 21, 1725.

Waddell, G, et al, Critical Care Medicine, 1974, 2, 68.

5 Waddell, G, British Medical fournal, 1975, 2, 417.

\section{University Department of Surgery, Western Infirmary, Glasgow} G11 6NT

G WADDELL, BSC, FRCS, senior orthopaedic registrar

B STUART, MB, FFARCs, anaesthetic registrar

M A TEHRANI, MD, FRCs, surgical research fellow

G MCGARRITY, BSC, FRCS, orthopaedic registrar

A REYES, MB, CHB, research fellow

H C SMITH, chief medical physics technician

I MCA LEDINGHAM, MB, CHB, consultant clinical physiologist

Division of Bioengineering, Clinical Research Centre, Watford Road, Harrow

H L GREEN, MB, DIC, consultant in clinical physiology C WELLER, DIC, MIEE, scientific worker 